\title{
A double-blind randomized trial on the clinical effect of different shunt valve settings in idiopathic normal pressure hydrocephalus
}

\author{
Dan Farahmand, MD, ${ }^{1}$ Terje Sæhle, MD, ${ }^{2}$ Per Kristian Eide, MD, PhD, ${ }^{2,3}$ Magnus Tisell, MD, PhD, ${ }^{1}$ \\ Per Hellström, PhD, ${ }^{1}$ and Carsten Wikkelsö, MD, PhD'1
}

${ }^{1}$ Hydrocephalus Research Unit, Institute of Neuroscience and Physiology, The Sahlgrenska Academy, University of Gothenburg, Gothenburg, Sweden; and ${ }^{2}$ Department of Neurosurgery and ${ }^{3}$ Faculty of Medicine, Oslo University Hospital, Oslo, Norway

OBJECTIVE The study aim was to examine the effect of gradually reducing the opening pressure on symptoms and signs in the shunt treatment of idiopathic normal pressure hydrocephalus (iNPH).

METHODS In this prospective double-blinded, randomized, controlled, double-center study on patients with iNPH, a ventriculoperitoneal shunt with an adjustable Codman Medos Valve was implanted in 68 patients randomized into 2 groups. In 1 group (the 20-4 group) the valve setting was initially set to $20 \mathrm{~cm} \mathrm{H}_{2} \mathrm{O}$ and gradually reduced to $4 \mathrm{~cm} \mathrm{H}_{2} \mathrm{O}$ over the course of the 6 -month study period. In the other group (the 12 group), the valve was kept at a medium level of $12 \mathrm{~cm} \mathrm{H}_{2} \mathrm{O}$ during the whole study period. All patients were clinically evaluated using 4 tests preoperatively as well as postoperatively at 1, 2, 3, 4, and 6 months. The test scores between the 2 groups (20-4 and 12) were compared for each clinical evaluation.

RESULTS Fifty-five patients (81\%) were able to complete the study. There were no significant differences between the 2 groups (20-4 and 12) preoperatively or at any time postoperatively. Both groups exhibited significant clinical improvement after shunt insertion at all valve settings compared with the preoperative score, with the greatest improvement observed at the first postoperative evaluation. The clinical improvement was significant within the first 3 months, and thereafter no significant improvement was seen in either group.

CONCLUSIONS Gradual reduction of the valve setting from 20 to $4 \mathrm{~cm} \mathrm{H}_{2} \mathrm{O}$ did not improve outcome compared with a fixed valve setting of $12 \mathrm{~cm} \mathrm{H} \mathrm{H}_{2} \mathrm{O}$. Improvement after shunt surgery in iNPH patients was evident within 3 months, irrespective of valve setting.

http://thejns.org/doi/abs/10.3171/2015.1.JNS141301

KEY WORDS randomized controlled trial; idiopathic normal pressure hydrocephalus; clinical effect; adjustable valve; shunt surgery; hydrocephalus; opening pressure

I DIOPATHIC normal pressure hydrocephalus (iNPH) is characterized by gait and postural disturbance, cognitive impairment, and urinary incontinence in connection with ventriculomegaly and normal intracranial pressure (ICP) ${ }^{10}$ The general treatment is implantation of a ventriculoperitoneal (VP) or ventriculoatrial (VA) shunt. Improvement rates after shunt surgery in iNPH have been reported to be $50 \%-90 \%$. $14,15,17,19,23,24,26$

However, complications following shunt surgery are common, ${ }^{11,16}$ especially subdural hematoma (SDH) seen in $2 \%-21 \%$ of iNPH patients treated with VP or VA shunts. ${ }^{7,8,15,21}$

Adjustable valves that permit the opening pressure to be changed externally have been recommended as a means of reducing the complication rate and enabling clinicians to optimize individual treatment. ${ }^{1,2}$

Randomized studies have indicated that lower opening pressure is related to better outcome ${ }^{5}$ but also to more overdrainage symptoms, ${ }^{6} \mathrm{SDH}$, and subdural effusions. ${ }^{5,6}$ Delwel et al. recommended that shunt treatment should be-

ABBREVIATIONS ASD = antisiphon device; BMI = body mass index; ICP = intracranial pressure; iNPH = idiopathic normal pressure hydrocephalus; ITT = intention-totreat; $\mathrm{RCT}$ = randomized controlled trial; $\mathrm{SDH}=$ subdural hematoma; SDS = standard deviation score (standardized score); tSDS = total SDS; VA = ventriculoatrial; VP = ventriculoperitoneal.

SUBMITTED June 14, 2014. ACCEPTED January 22, 2015.

INCLUDE WHEN CITING Published online August 28, 2015; DOI: 10.3171/2015.1.JNS141301. 
gin with the valve set at a high opening pressure, followed by a gradual reduction until the optimal individual level is reached. ${ }^{6}$

Randomized studies by Boon et al. have indicated that lower opening pressure is related to better outcome but also to more overdrainage symptoms. ${ }^{5}$ This was not confirmed in another Dutch trial showing no clinical effect of a lower opening pressure but a higher complication rate leading to the recommendation that shunt treatment should begin with the valve set at a high opening pressure, followed by a gradual reduction until the optimal individual level is reached. ${ }^{6}$

The aim of this study was to examine the clinical effect of gradually reducing the opening pressure on symptoms and signs of iNPH in a double-blind, double-center, randomized controlled trial (RCT) to assess the optimal use of adjustable valves.

\section{Methods \\ Patients}

Sixty-eight patients with a median age of 71 years (range 50-89) were included from July 2007 to July 2011; 46 from Sahlgrenska University Hospital, Gothenburg, Sweden, and 22 from Oslo University Hospital, Oslo, Norway. Exclusion criteria were previous shunt placement, inability to walk, and short life expectancy due to serious illness.

The diagnosis of probable iNPH was based on characteristic symptoms and signs, ventriculomegaly with an Evans index $>0.3$, normal ICP, and an open cerebral aqueduct verified by MRI in accordance with the guideline criteria. ${ }^{18}$ ICP was measured between 11 PM and 7 AM in Oslo and in Gothenburg during 10 minutes at the start of a CSF dynamic examination.

Patients included in Oslo also had to present with abnormal ICP dynamics defined as mean ICP wave amplitude above $4 \mathrm{~mm} \mathrm{Hg}$ and $>5 \mathrm{~mm} \mathrm{Hg}$ for at least $10 \%$ of the recording time. ${ }^{7}$ All eligible patients agreed to participate.

\section{Study Design}

The study design was double-blind, double-center with randomization in blocks of 4 . The randomization was common for the 2 centers. Immediately prior to shunt surgery the randomization was performed by opening a sealed envelope containing a note that divided the patients into 1 of 2 groups (20-4 or 12). Demographic data are presented in Table 1.

Only an independent research nurse was aware of the groupings. In the 20-4 group the valve was set to $20 \mathrm{~cm}$ $\mathrm{H}_{2} \mathrm{O}$ at the time of shunt insertion and lowered by $4 \mathrm{~cm}$ $\mathrm{H}_{2} \mathrm{O}$ each month immediately after a standardized clinical evaluation (Fig. 1). Hence, the final valve setting of $4 \mathrm{~cm}$ $\mathrm{H}_{2} \mathrm{O}$ was reached 4 months postoperatively.

In group 12 the opening pressure was maintained at $12 \mathrm{~cm} \mathrm{H}_{2} \mathrm{O}$ from shunt insertion to the end of the study. To prevent bias, the monthly valve adjustments were performed by a researcher who was not involved in the clinical evaluations. Both patients and evaluators were blind to the valve settings during the study period. The 2 study groups underwent the monthly valve adjustment proce-
TABLE 1. Demographic data of patients in the 20-4 and 12 groups*

\begin{tabular}{lllc}
\hline \multicolumn{1}{c}{ Variables } & $\begin{array}{c}\text { Group 20-4 } \\
(\mathrm{n}=34)\end{array}$ & $\begin{array}{c}\text { Group 12 } \\
(\mathrm{n}=34)\end{array}$ & $\mathrm{p}$ Value \\
\hline Mean age in yrs (SD) & $70.3(8.2)$ & $71.1(7.7)$ & 0.58 \\
\hline Sex, male/female & $20 / 14$ & $23 / 11$ & 0.62 \\
\hline Mean BMl in $\mathrm{kg} / \mathrm{m}^{2}(\mathrm{SD})$ & $26.2(3.3)$ & $26.1(4.1)$ & 0.96 \\
\hline ASD, yes $/ \mathrm{no}$ & $24 / 10$ & $22 / 12$ & 0.80 \\
\hline
\end{tabular}

* The variables did not differ significantly between the groups.

dure, but in group 12 , the valve was merely readjusted to the same setting.

At the time of the postoperative clinical evaluations, the patients in both groups were questioned about symptoms. If a complication was suspected, a CT scan of the head and plain radiographs of the head, chest, and abdomen were obtained. If these evaluations did not lead to a conclusion regarding shunt dysfunction, patients in Gothenburg were examined with shuntography ${ }^{25}$ and those in Oslo by ICP monitoring.

In the event of complications or overdrainage symptoms, the randomization code was broken, and the patient was treated and kept in the study at the optimal valve setting, without further valve adjustments until the final evaluation at 6 months.

\section{Shunt Surgery}

All patients received a VP shunt with a Codman Hakim programmable valve (Codman \& Schurtleff/Johnson \& Johnson Co.). Shunt insertion was performed with the ventricular catheter placed in the right lateral ventricle through a frontal bur hole and the distal catheter tip in the abdominal cavity. All patients operated on in Gothenburg received shunts with an antisiphon device (ASD, Siphon Guard), whereas those operated on in Oslo received shunts without an ASD.

\section{Clinical Assessment}

Preoperatively, as well as at 1, 2, 3, 4, and 6 months postoperatively, all patients were clinically evaluated using 4 tests. Immediately after each evaluation, the valves were adjusted in both groups as shown in Fig. 1.

The 4 tests were 1) the number of steps needed to walk $10 \mathrm{~m}$ (walk steps), 2) the number of seconds it took to walk $10 \mathrm{~m}$ (walk time), 3) the color-naming task of the Stroop test,$^{13}$ and 4) the Grooved Pegboard test..$^{13}$ The time and number of steps needed to walk $10 \mathrm{~m}$ were measured by instructing the patients to start at a designated line and walk as quickly as possible on an indoor floor without any slope to another line $10 \mathrm{~m}$ further away. The time (seconds) was measured using a stopwatch, and the number of steps needed to reach a line $10 \mathrm{~m}$ away was registered. In the color-naming task of the Stroop test, the patients were asked to name the colors of 100 rectangles presented in 10 rows on a sheet of paper as quickly as possible. ${ }^{13} \mathrm{In}$ the Grooved Pegboard test the patients were instructed to place 25 pegs into holes with randomly positioned slots as 


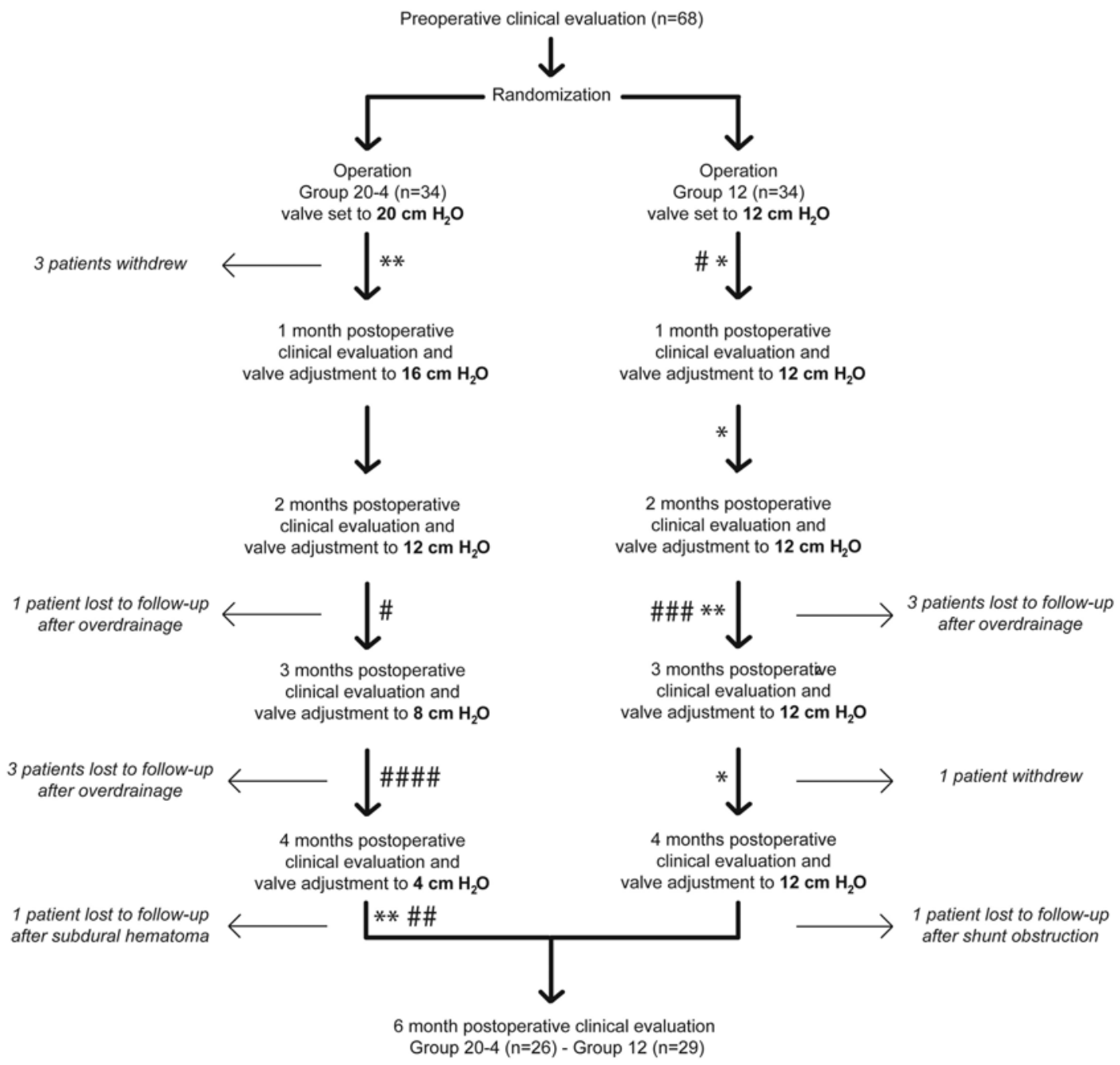

FIG. 1. Flow diagram of the randomization and clinical evaluations during the study. Patients lost to follow-up are presented in the diagram. Complete follow-up was achieved in 55 of the 68 patients included. The asterisks indicate an SDH event, and the number signs represent over drainage symptoms. The time points at which patients were lost to follow-up or withdrew from the study are indicated by horizontal arrows.

quickly as possible while the time required to complete the task was measured. ${ }^{13}$

\section{Statistical Analysis}

To compare the scores of the 4 monthly tests, a standard deviation score (SDS, also known as standardized score) was generated based on the preoperative test mean score (mean-preoperative) and standard deviation (SDpreoperative) for all patients. The SDS of the individual test score was calculated using the following equation: SDS = (mean-preoperative - individual test score $) / S D$ preoperative.

The total SDS (tSDS) was calculated for each patient as the mean of the SDS for the 4 monthly tests.

The magnitude of individual changes between separate postoperative assessments in both groups was quantified by comparing the change of each individual (e.g., tSDS at 3 months - tSDS at 2 months) with the joint distribution of tSDS changes between all pairs of consecutive post- operative assessments in the 12 group. This distribution served as a reference distribution for changes. Here, we arbitrarily defined significant changes as those exceeding $1 \mathrm{SD}$ of the reference distribution. The purpose of this method was to enable us to determine whether patients in the 20-4 group tended to exhibit more marked changes (in comparison with patients in the 12-group) at certain valve settings. The primary outcome variable was the difference in tSDS at each monthly follow-up evaluation between the 2 groups. For comparisons between the groups, the Fisher exact test was used for dichotomous variables, and the Mann-Whitney U-test was used for continuous variables. Due to site differences, an adjustment of $\mathrm{p}$ values for tests between groups was performed using van Elteren's test with site as a blocking variable. Changes over time since the preoperative visit were assessed by the Wilcoxon signed-rank test for all 4 tests separately as well as for their mean value. To compare the final treatment results (both in terms of scale scores and tSDS) be- 
tween the 2 groups, we used analysis of covariance with the preoperative result as a covariate, thus adjusting for the preoperative level of severity.

For the intention-to-treat (ITT) analysis, the MannWhitney U-test was used to compare the difference between pre- and postoperative (last observation carried forward) tSDS.

All tests were 2-tailed and conducted at the 0.05 significance level. The analyses were performed using SAS version 9.2.

\section{Ethical Aspects}

The study was approved by the Regional Ethical Review Board in Gothenburg, the Regional Committee for Medical and Health Research Ethics, and the hospital authority of Oslo University Hospital. All participating patients provided written informed consent. This trial was not registered because the start date (July 2007) predated the requirement for registration.

\section{Results}

Fifty-five patients $(81 \%)$ took part in the 6 -month postoperative clinical evaluation (see Fig. 1).

At the end of the study, 18 of the 26 patients in the 20-4 group had a valve setting of $4 \mathrm{~cm} \mathrm{H}_{2} \mathrm{O}, 7$ patients had a setting of $12 \mathrm{~cm} \mathrm{H}_{2} \mathrm{O}$, and 1 had a setting of $16 \mathrm{~cm} \mathrm{H}_{2} \mathrm{O}$. In the 12 group, 25 patients had a valve setting of $12 \mathrm{~cm}$ $\mathrm{H}_{2} \mathrm{O}, 2$ had a setting of $20 \mathrm{~cm} \mathrm{H}_{2} \mathrm{O}$, and 2 had a setting of $10 \mathrm{~cm} \mathrm{H}_{2} \mathrm{O}$. Thus, the mean valve setting at the end of the study was $7 \mathrm{~cm} \mathrm{H}_{2} \mathrm{O}$ in the 20-4 group and $13 \mathrm{~cm} \mathrm{H}_{2} \mathrm{O}$ in the 12 group.

The members of both the 20-4 and the 12 groups were improved significantly in tSS after shunt insertion at all valve settings compared with the preoperative score, and they exhibited the greatest improvement at the first postoperative evaluation. There were no significant differences between the 2 groups preoperatively or at any time postoperatively (Table 2, raw scores are presented in Table 3).

The raw data of the 4 tests are presented in the Table 3. There were no significant differences in the SDS for any of the 4 tests or in the tSDS between the 20-4 and 12 groups at any time postoperatively (Figs. 2 and 3), either when all patients (regardless of actual final valve setting) or when only those who on completion of the study had the intended settings of $4 \mathrm{~cm}$ and $12 \mathrm{~cm}$, respectively, were included in the analyses. The inclusion of the preoperative tSDS score as a covariate did not change the results.

The improved tSDS could be observed in both groups within the first 3 months ( $p<0.001)$, and thereafter no significant improvement was seen in either group (Figs. 2 and 3). The intention-to-treat analysis did not show any difference in tSDS between the 2 groups $(\mathrm{p}=0.169)$.

Thirty-one patients from both groups improved more than 1 SD of the tSDS changes between all pairs of consecutive postoperative SDS in the 12 group, and none of the patients deteriorated by more than 1 SD. Twenty-six patients (84\%) improved in the course of the first 3 postoperative months compared with 5 patients in the last 3 months (Fig. 4), with no difference between the groups.
TABLE 2. Mean tSDS at the monthly clinical evaluations in the 2 groups (20-4 and 12)*

\begin{tabular}{lcc}
\hline \multirow{1}{*}{ Time Point } & \multicolumn{2}{c}{ Mean tSDS (SD) } \\
\cline { 2 - 3 } & Group 20-4 & Group 12 \\
\hline Preop tSDS & $-0.23(1.10)$ & $0.09(0.67)$ \\
& $\mathrm{n}=32$ & $\mathrm{n}=34$ \\
\hline 1-mo-postop tSDS valve setting & $0.21(0.61)$ & $0.37(0.33)$ \\
$20 \mathrm{~cm} \mathrm{H}_{2} \mathrm{O}$ & $\mathrm{n}=29$ & $\mathrm{n}=32$ \\
\hline 2-mo-postop tSDS valve setting & $0.38(0.45)$ & $0.47(0.36)$ \\
$16 \mathrm{~cm} \mathrm{H}_{2} \mathrm{O}$ & $\mathrm{n}=29$ & $\mathrm{n}=29$ \\
\hline 3 -mo-postop tSDS valve setting & $0.44(0.41)$ & $0.47(0.38)$ \\
$12 \mathrm{~cm} \mathrm{H}_{2} \mathrm{O}$ & $\mathrm{n}=28$ & $\mathrm{n}=25$ \\
\hline 4 -mo-postop tSDS valve setting & $0.43(0.39)$ & $0.52(0.38)$ \\
$8 \mathrm{~cm} \mathrm{H} \mathrm{O}$ & $\mathrm{n}=22$ & $\mathrm{n}=21$ \\
\hline 6 -mo-postop tSDS valve setting & $0.46(0.27)$ & $0.52(0.30)$ \\
$4 \mathrm{~cm} \mathrm{H}_{2} \mathrm{O}$ & $\mathrm{n}=23$ & $\mathrm{n}=27$ \\
\hline
\end{tabular}

* All postoperative tSDSs were significantly $(p<0.05)$ higher compared to preoperatively. There were no significant differences between the 2 groups preoperatively or at any time postoperatively. As a result of missing data, the denominators of both groups at follow-up differed between evaluations.

\section{Discussion}

This study revealed that a gradual reduction of the valve setting from $20 \mathrm{~cm} \mathrm{H}_{2} \mathrm{O}$ to $4 \mathrm{~cm} \mathrm{H}_{2} \mathrm{O}$ made no clinical difference compared with a fixed valve setting of 12 $\mathrm{cm} \mathrm{H}_{2} \mathrm{O}$. Nor did a reduction in valve setting have any effect on the number of "significant" improvements compared with a fixed setting. Explicitly, no clinical changes were observed when the valve setting was lowered from 12 to $4 \mathrm{~cm} \mathrm{H}_{2} \mathrm{O}$.

The literature on the effect of low versus medium or high valve settings on outcome is conflicting. Boon et al. found that all outcome measures indicated trends in favor of the low pressure valve compared with medium pressure shunts, with only the dementia scale reaching a significant difference. After exclusion of serious events and deaths unrelated to NPH, efficacy analysis demonstrated the advantage of low pressure valve shunts to be diminished. ${ }^{5}$ Despite this nonsignificant result in terms of outcome and a higher complication rate in the low-pressure valve group, the Dutch group recommended the use of low opening pressure valves for treatment of NPH, a recommendation which has influenced the discussion in this area for many years. In another randomized Dutch study, Delwel et al. tested the hypothesis that patients treated with an adjustable valve (Strata valves set to 2.5, Medtronic) preset at the highest opening pressure would have comparably good clinical results with less subdural effusion compared with a control group with a low preset opening pressure (Strata set to 1.0). They found significantly more subdural effusion in the low pressure group but no significant difference with regard to improvement. Interestingly, the 2 groups had a large difference in valve settings at the end of the study, where only 1 patient had a valve setting below 1.5 in the high setting group, and only 3 patients had a setting above 1.0 in the low setting group. ${ }^{6}$ A recalculation of their results shows that the median valve setting at the end 
TABLE 3. Means and SDs of the raw data for the 4 monthly tests in the 2 groups (20-4 and 12)

\begin{tabular}{|c|c|c|c|c|}
\hline \multirow[b]{2}{*}{ Evaluation } & \multicolumn{2}{|c|}{ Group 20-4 } & \multicolumn{2}{|r|}{ Group 12} \\
\hline & Raw Data & Improvement From Preop & Raw Data & Improvement From Preop \\
\hline \multicolumn{5}{|c|}{ Stroop test in seconds } \\
\hline Preop & $105.7(76.3)$ & - & $83.6(48.1)$ & - \\
\hline 1 mo postop & $88.8(36.8)$ & $17.9(60.6)^{*}$ & $76.9(28.8)$ & $7.10(31.14)$ \\
\hline 2 mos postop & $80.8(30.3)$ & $25.8(60.7)^{*}$ & $71.6(27.1)$ & $7.61(19.65)$ \\
\hline 3 mos postop & $77.0(27.0)$ & $32.1(66.4)^{*}$ & $71.4(26.1)$ & $10.1(24.1)^{*}$ \\
\hline 4 mos postop & $79.2(22.6)$ & $37.4(75.4)^{*}$ & $70.7(29.5)$ & $11.4(23.6)^{*}$ \\
\hline 6 mos postop & $78.8(22.0)$ & $37.4(75.4)^{*}$ & $69.3(26.7)$ & $11.4(23.6)^{*}$ \\
\hline \multicolumn{5}{|c|}{$\begin{array}{l}\text { Grooved Pegboard test in } \\
\text { seconds }\end{array}$} \\
\hline Preop & $150.1(81.7)$ & - & $163.8(123.1)$ & - \\
\hline 1 mo postop & $134.9(83.2)$ & $13.8(24.9)^{*}$ & $131.0(61.5)$ & $19.8(56.3)$ \\
\hline 2 mos postop & $115.8(49.8)$ & $33.8(61.1)^{*}$ & $114.4(42.7)$ & $25.9(56.0)^{*}$ \\
\hline 3 mos postop & $107.4(39.1)$ & $40.5(59.2)^{*}$ & $106.4(32.8)$ & $23.4(45.3)^{*}$ \\
\hline 4 mos postop & $97.6(32.4)$ & $49.0(64.0)^{*}$ & $105.4(30.0)$ & $30.7(41.8)^{\star}$ \\
\hline 6 mos postop & $97.5(40.8)$ & $49.0(64.0)^{*}$ & $97.7(27.0)$ & $30.7(41.8)^{*}$ \\
\hline \multicolumn{5}{|c|}{ Walk time in seconds } \\
\hline Preop & $12.4(7.7)$ & - & $10.3(4.5)$ & - \\
\hline 1 mo postop & $9.98(6.43)$ & $2.41(4.52)^{*}$ & $8.81(2.80)$ & $1.55(3.47)^{*}$ \\
\hline 2 mos postop & $8.71(3.66)$ & $3.73(5.17)^{\star}$ & $8.50(2.92)$ & $2.23(3.23)^{*}$ \\
\hline 3 mos postop & $8.39(3.27)$ & $4.15(5.94)^{*}$ & $8.46(3.41)$ & $2.40(3.21)^{\star}$ \\
\hline 4 mos postop & $8.24(3.58)$ & $4.49(6.77)^{\star}$ & $8.00(3.62)$ & $2.78(3.65)^{*}$ \\
\hline 6 mos postop & $7.35(1.56)$ & $4.49(6.77)^{*}$ & $7.69(2.50)$ & $2.78(3.65)^{*}$ \\
\hline \multicolumn{5}{|c|}{ Walk steps, no. of steps } \\
\hline Preop & $21.0(11.4)$ & - & $17.6(7.0)$ & - \\
\hline 1 mo postop & $17.2(8.5)$ & $3.80(6.11)^{*}$ & $15.2(3.4)$ & $2.68(6.07)^{*}$ \\
\hline 2 mos postop & $15.7(5.2)$ & $5.41(8.06)^{*}$ & $14.7(3.5)$ & $3.25(6.06)^{\star}$ \\
\hline 3 mos postop & $15.1(4.9)$ & $6.09(8.68)^{*}$ & $15.0(4.5)$ & $3.67(5.78)^{\star}$ \\
\hline 4 mos postop & $15.6(5.6)$ & $6.62(9.50)^{*}$ & $14.3(3.9)$ & $4.52(6.72)^{*}$ \\
\hline 6 mos postop & $15.0(2.2)$ & $6.62(9.50)^{*}$ & $14.3(3.9)$ & $4.52(6.72)^{*}$ \\
\hline
\end{tabular}

* Significant $(p<0.05)$ postoperative improvements in the SDSs.

of the study was 2.0 in the high setting group and half (1.0) in the low setting group. The results of Delwel et al. are consistent with the present study, where the mean valve setting in the 20-4 group at the end of the study was approximately half of that in the 12 group ( $7 \mathrm{vs} 13 \mathrm{~cm} \mathrm{H}_{2} \mathrm{O}$ ), with no difference in outcome.

This study demonstrated that valve settings below 12 $\mathrm{cm} \mathrm{H}_{2} \mathrm{O}$ had no impact on outcome, which is consistent with the findings of Delwel et al. but contradicts the results of Boon et al., which indicated a possible effect. Is there any explanation or hypothesis for why lowering the valve setting makes no difference to the outcome? One explanation could be that valve setting has a very limited effect on the actual ICP. This is supported by the results of Bergsneider et al. ${ }^{3}$ showing the relationship between ICP and opening pressure (VP Codman Hakim programmable valves) to be linear but not predictable by simple hydrodynamics. These authors also noted that the actual ICP in the supine position only changed approximately $1.2 \mathrm{~cm}$ $\mathrm{H}_{2} \mathrm{O}$ for each adjustment intended to correspond to $3 \mathrm{~cm}$.
Similarly, Farahmand et al. ${ }^{9}$ found the maximal adjustability difference (highest vs lowest valve setting, Strata valves) to be only $4.4 \mathrm{~mm} \mathrm{Hg}$ (i.e., $6 \mathrm{~cm} \mathrm{H}_{2} \mathrm{O}$ instead of the intended adjustability difference of somewhere between 10 and $14 \mathrm{~cm} \mathrm{H}_{2} \mathrm{O}$ ). Another possible explanation could be that changing ICP within the normal range by means of valve settings has no effect on symptoms and signs as long as there is a functioning absorption mechanism with low resistance to outflow. ICP varies widely during the day depending on, for example, body position and venous pressure, and these variations might be more important for absorption than the resting pressure. Implanting a shunt with low resistance immediately establishes an alternative absorption route for CSF at all ICP levels. As the shunt resistance is lower than the resistance to outflow prior to surgery, (periventricular?) CSF absorption should always take place through the shunt system, irrespective of the ICP level. Both concepts offer a plausible explanation as to why the effect of shunt surgery is independent of the valve setting. 


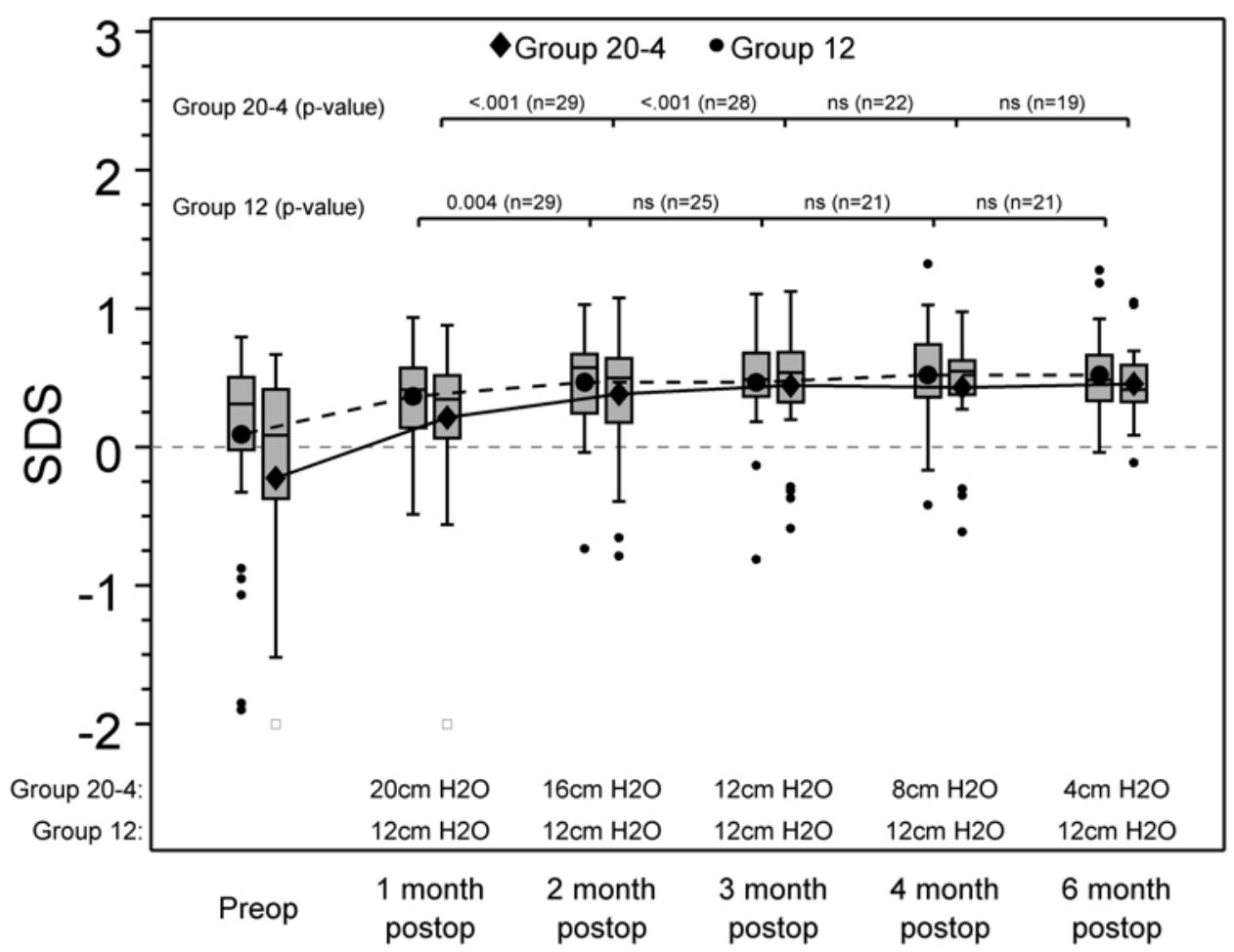

FIG. 2. Box and whisker plot showing the change in the mean tSDS between the clinical evaluations in the 2 groups (20-4 and 12). A trend line is drawn between the mean SDS values for each group. Above the trend lines, the $p$ values of the different valve adjustments are indicated ( $n=$ number of paired analyses). The whiskers denote values within the 1.5 interquartile range from the first and third quartile, dots represent outliers, and the 2 small boxes indicate outliers not fitted into the plot scale.

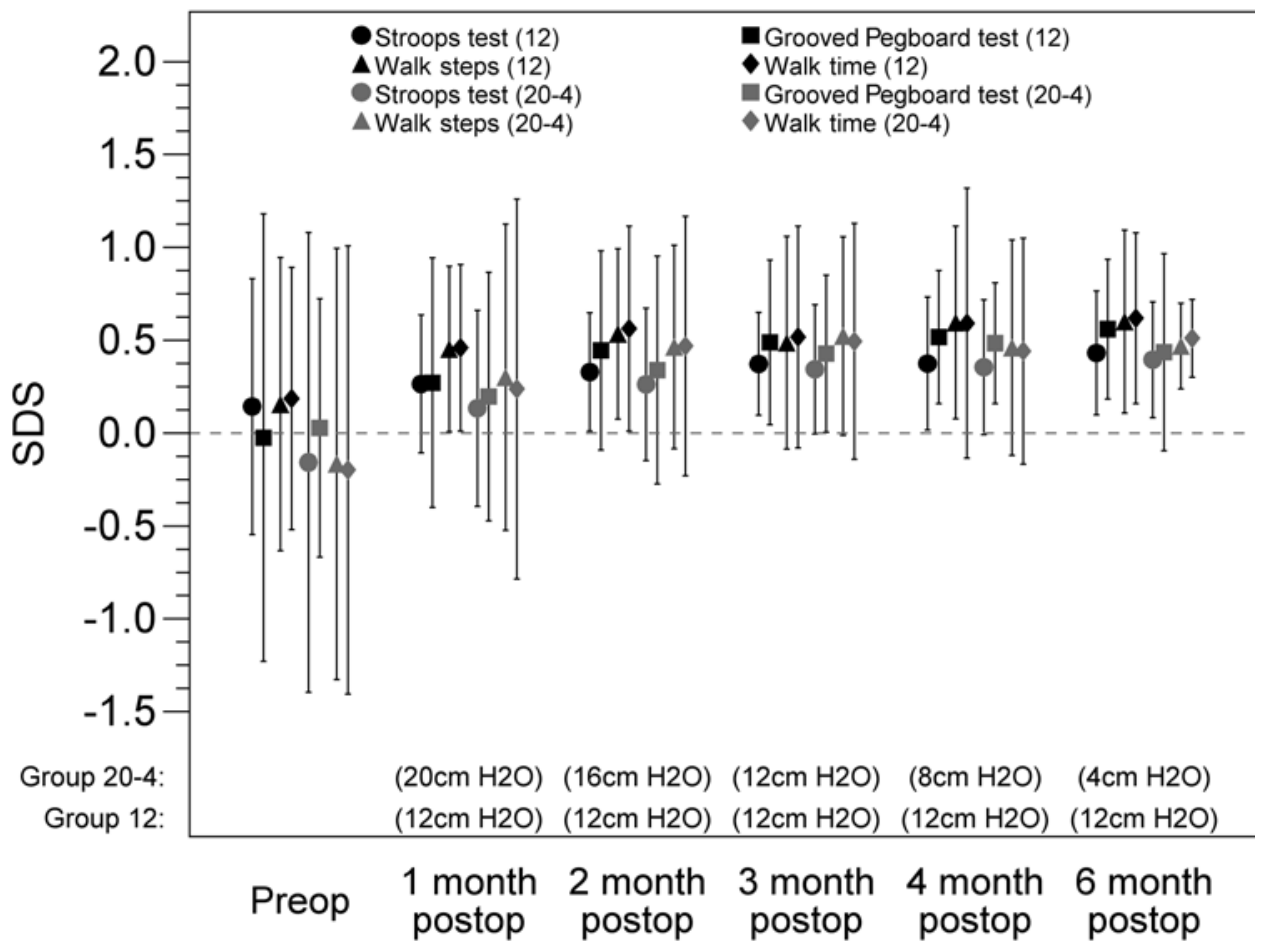

FIG. 3. Mean SDS of each of the 4 tests repeated on a monthly basis after valve adjustments. 


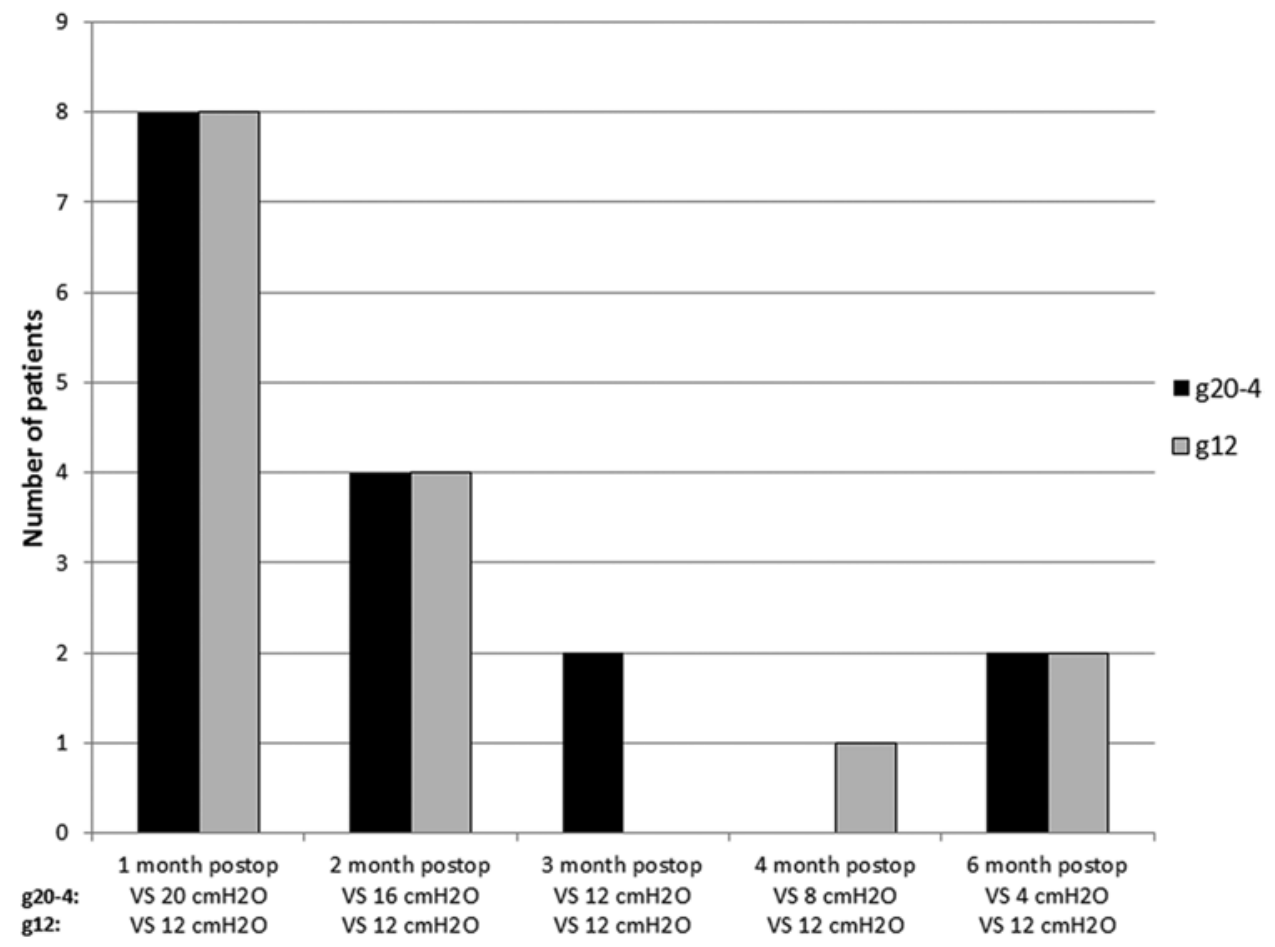

FIG. 4. Bar graph showing number of patients who improved by more than 1 SD of the postoperative SDS in the 12 group (reference group) for the 20-4 group (g20-4) and the 12 group (g12). There was no deterioration in any patient's condition. The valve settings for the 2 groups at each of the monthly evaluations are presented below the $x$-axis.

Unfortunately, no group in the present study was treated by means of a valve with a fixed setting of $20 \mathrm{~cm} \mathrm{H}_{2} \mathrm{O}$. However, it is interesting to note that most of the improvement seen in group 20-4 (0.44 of the 0.69 total increase in tSS) occurred with a valve setting of $20 \mathrm{~cm} \mathrm{H}_{2} \mathrm{O}$, supporting the significance of reduced resistance to outflow in favor of changing the ICP. Delwel et al. observed a similar positive outcome in the group treated with high valve settings (mean $20 \mathrm{~cm}$ ).

The clinical effect of shunting appeared within 3 months after insertion of the shunt, irrespective of the initial valve setting $\left(20\right.$ or $12 \mathrm{~cm} \mathrm{H}_{2} \mathrm{O}$ ) and without significant differences between the groups. No further improvement was seen when the valve setting was below $12 \mathrm{~cm} \mathrm{H}_{2} \mathrm{O}$. This is a reason for evaluating iNPH patients 3 months after shunt implantation.

In a recent article based on the patients in this study we reported an improvement of iNPH scale score or NPH grading scale in $88 \%$ of the patients in the 20-4 group compared with $62 \%$ in the 12 group..$^{20}$ The reason for the apparent discrepancy between our 2 articles is that they are based on different methods. First, our current article defines the results based on a set of objective tests while the previous article was partly based on the patient's subjective descriptions of the overall effect during the followup period. Secondly, in the previous article we did not use statistical methods to adjust for the inequality of the preoperative results of the 2 groups. It has been shown that patients with more severe symptoms show a greater improvement than less impaired patients on the tests included in this study. ${ }^{12}$
The complication rate between the 2 groups (20-4 and 12) was recently published, showing no significant difference in the complication rate..$^{20}$

To our knowledge, this is the first RCT to explore the clinical effect of lowering the valve setting. Previous nonrandomized and nonblinded studies ${ }^{2,4,6,27}$ have indicated that changing the opening pressure may have significant effects on symptoms and signs. In this study, we found no evidence to support this notion. Changing the valve setting in steps of $4 \mathrm{~cm} \mathrm{H}_{2} \mathrm{O}$ had no clinical effect above and beyond that observed with valves fixed at $12 \mathrm{~cm} \mathrm{H}_{2} \mathrm{O}$, a finding that strongly calls into question the rationale behind repeated valve setting changes. A new RCT to specifically address this issue should be performed to obtain evidencebased data. The reason why stepwise changing of the valve setting has no effect could be explained by the factors discussed above. Adjustable shunts seem valuable for the management of complications, such as SDH and effusions, as well as symptoms related to over- and underdrainage. ${ }^{20}$

For the practical purpose of repeated evaluations, it was important to select easy to administer tests from the iNPH scale for this study. The 4 tests were carefully chosen to prevent the risk of learning effects leading to improved test results. A previous study involving patients with NPH did not indicate any learning effect on neuropsychological and motor tasks; ${ }^{22}$ therefore, we believe that such an effect between the evaluations in this study was negligible. The validity of the test battery is illustrated by the very small difference in the analyzed probability of improvement 6 months postoperatively between the iNPH/NPH scale and the mean SDS of only $0.07 .^{20}$ 
Although both centers followed the same study protocol, some conditions differed between the 2 sites. First, different individuals administered the 4 clinical tests at the 2 centers (Gothenburg and Oslo), thus the results include an unknown degree of interobserver variability. Second, the guideline criteria for probable iNPH were used at both centers, but in Oslo the patients were also required to have mean ICP wave amplitude above $4 \mathrm{~mm} \mathrm{Hg}$ and $>5 \mathrm{~mm} \mathrm{Hg}$ for at least $10 \%$ of the recording time. The CSF dynamic testing in Oslo was an established evaluation procedure that we decided to retain, as changing local policies often results in more problems than benefits. Finally, due to administrative policies at each hospital, we also decided to retain the established routines for shunts with an ASD in Gothenburg and shunts without an ASD in Oslo. As we have recently published, the same rate of SDH was observed in patients with and without ASD, but a significantly higher rate of overdrainage symptoms was seen in the patients without ASD $(\mathrm{p}=0.002) .{ }^{20}$

The sample size of 60 was deemed appropriate based on the assumption of a complication rate of 30\% (SD 8\%) and a power of $90 \%$. At the time we planned the study no data were available on the expected clinical effect. During the 6-month study period, the amount of missing data were $16 \%$, mainly due to patients lost to follow-up after SDH or overdrainage symptoms and patients withdrawing from the study. There were no significant differences in patient cohort characteristics (age, sex, height, weight, and body mass index) between the 2 sites, indicating a comparable patient selection. Since most patients at both centers had to travel a great distance for the follow-up evaluations due to the large catchment areas, patients who were unable to attend all of the appointments were an additional source of missing data.

The total improvement rate in the present study (75\%) was comparable to previous studies, ${ }^{7,16,17,19}$ thus supporting the diagnostic validity. The patients were selected according to the classic criteria at both centers and we believe that both they and the results are representative of iNPH.

\section{Conclusions}

Gradual reduction of the valve setting from 20 to $4 \mathrm{~cm}$ $\mathrm{H}_{2} \mathrm{O}$ did not improve outcome compared with a fixed valve setting of $12 \mathrm{~cm} \mathrm{H}_{2} \mathrm{O}$, nor did such adjustments give rise to a greater number of significant improvements at postadjustment examinations compared with a fixed setting.

Improvement after shunt surgery in iNPH patients was evident within 3 months, irrespective of valve setting, and lowering the setting to below $12 \mathrm{~cm} \mathrm{H}_{2} \mathrm{O}$ did not further improve outcomes.

\section{Acknowledgment}

Statistical analyses were performed by Aldina Pivodic of Statistiska Konsultgruppen.

\section{References}

1. Bergsneider M: Management of hydrocephalus with programmable valves after traumatic brain injury and subarachnoid hemorrhage. Curr Opin Neurol 13:661-664, 2000

2. Bergsneider M, Black PM, Klinge P, Marmarou A, Relkin N:
Surgical management of idiopathic normal-pressure hydrocephalus. Neurosurgery 57 (3 Suppl):S29-S39, ii-v, 2005

3. Bergsneider M, Yang I, Hu X, McArthur DL, Cook SW, Boscardin WJ: Relationship between valve opening pressure, body position, and intracranial pressure in normal pressure hydrocephalus: paradigm for selection of programmable valve pressure setting. Neurosurgery 55:851-859, 2004

4. Black PM, Hakim R, Bailey NO: The use of the CodmanMedos Programmable Hakim valve in the management of patients with hydrocephalus: illustrative cases. Neurosurgery 34:1110-1113, 1994

5. Boon AJ, Tans JT, Delwel EJ, Egeler-Peerdeman SM, Hanlo PW, Wurzer HA, et al: Dutch Normal-Pressure Hydrocephalus Study: randomized comparison of low- and mediumpressure shunts. J Neurosurg 88:490-495, 1998

6. Delwel EJ, de Jong DA, Dammers R, Kurt E, van den Brink W, Dirven CM: A randomised trial of high and low pressure level settings on an adjustable ventriculoperitoneal shunt valve for idiopathic normal pressure hydrocephalus: results of the Dutch evaluation programme Strata shunt (DEPSS) trial. J Neurol Neurosurg Psychiatry 84:813-817, 2013

7. Eide PK, Sorteberg W: Diagnostic intracranial pressure monitoring and surgical management in idiopathic normal pressure hydrocephalus: a 6-year review of 214 patients. Neurosurgery 66:80-91, 2010

8. Farahmand D, Hilmarsson H, Högfeldt M, Tisell M: Perioperative risk factors for short term shunt revisions in adult hydrocephalus patients. J Neurol Neurosurg Psychiatry 80:1248-1253, 2009

9. Farahmand D, Qvarlander S, Malm J, Wikkelsö C, Eklund A, Tisell M: Intracranial pressure in hydrocephalus: impact of shunt adjustments and body positions. J Neurol Neurosurg Psychiatry 86:222-228, 2015

10. Hakim S, Adams RD: The special clinical problem of symptomatic hydrocephalus with normal cerebrospinal fluid pressure. Observations on cerebrospinal fluid hydrodynamics. J Neurol Sci 2:307-327, 1965

11. Hebb AO, Cusimano MD: Idiopathic normal pressure hydrocephalus: a systematic review of diagnosis and outcome. Neurosurgery 49:1166-1186, 2001

12. Hellström P, Edsbagge M, Blomsterwall E, Archer T, Tisell M, Tullberg M, et al: Neuropsychological effects of shunt treatment in idiopathic normal pressure hydrocephalus. Neurosurgery 63:527-536, 2008

13. Hellström P, Klinge P, Tans J, Wikkelsø C: A new scale for assessment of severity and outcome in iNPH. Acta Neurol Scand 126:229-237, 2012

14. Kahlon B, Sjunnesson J, Rehncrona S: Long-term outcome in patients with suspected normal pressure hydrocephalus. Neurosurgery 60:327-332, 2007

15. Klinge P, Hellström P, Tans J, Wikkels $\varnothing$ C: One-year outcome in the European multicentre study on iNPH. Acta Neurol Scand 126:145-153, 2012

16. Klinge P, Marmarou A, Bergsneider M, Relkin N, Black PM: Outcome of shunting in idiopathic normal-pressure hydrocephalus and the value of outcome assessment in shunted patients. Neurosurgery 57 (3 Suppl):S40-S52, ii-v, 2005

17. Malm J, Kristensen B, Stegmayr B, Fagerlund M, Koskinen LO: Three-year survival and functional outcome of patients with idiopathic adult hydrocephalus syndrome. Neurology 55:576-578, 2000

18. Marmarou A, Black P, Bergsneider M, Klinge P, Relkin N: Guidelines for management of idiopathic normal pressure hydrocephalus: progress to date. Acta Neurochir Suppl 95:237-240, 2005

19. Marmarou A, Young HF, Aygok GA, Sawauchi S, Tsuji O, Yamamoto T, et al: Diagnosis and management of idiopathic normal-pressure hydrocephalus: a prospective study in 151 patients. J Neurosurg 102:987-997, 2005 
20. Sæhle T, Farahmand D, Eide PK, Tisell M, Wikkelsö C: A randomized controlled dual-center trial on shunt complications in idiopathic normal-pressure hydrocephalus treated with gradually reduced or "fixed" pressure valve settings. J Neurosurg 121:1257-1263, 2014

21. Samuelson S, Long DM, Chou SN: Subdural hematoma as a complication of shunting procedures for normal pressure hydrocephalus. J Neurosurg 37:548-551, 1972

22. Solana E, Poca MA, Sahuquillo J, Benejam B, Junqué C, Dronavalli M: Cognitive and motor improvement after retesting in normal-pressure hydrocephalus: a real change or merely a learning effect? J Neurosurg 112:399-409, 2010

23. Tisell M, Hellström P, Ahl-Börjesson G, Barrows G, Blomsterwall E, Tullberg M, et al: Long-term outcome in 109 adult patients operated on for hydrocephalus. Br J Neurosurg 20:214-221, 2006

24. Toma AK, Papadopoulos MC, Stapleton S, Kitchen ND, Watkins LD: Systematic review of the outcome of shunt surgery in idiopathic normal-pressure hydrocephalus. Acta Neurochir (Wien) 155:1977-1980, 2013

25. Wikkelso C, Andersson H, Lindberg S, Blomstrand C: "Shuntography"- a radionuclide scanning method for evaluation of cerebrospinal fluid shunt patency. Nucl Med Commun 4:88-93, 1983

26. Virhammar J, Laurell K, Cesarini KG, Larsson EM: The callosal angle measured on MRI as a predictor of outcome in idiopathic normal-pressure hydrocephalus. J Neurosurg 120:178-184, 2014
27. Zemack G, Romner B: Adjustable valves in normal-pressure hydrocephalus: a retrospective study of 218 patients. Neurosurgery 51:1392-1402, 2002

\section{Disclosure}

This study was supported by unrestricted grants from the Göteborg Medical Society, the Edit Jacobson Foundation, the John and Britt Wennerström Foundation, and the Per-Olof Ahl Foundation for research on vascular diseases of the brain. Dr. Wikkelsö reports receiving honoraria as lecturer for Johnson \& Johnson.

\section{Author Contributions}

Conception and design: Eide, Tisell, Wikkelsö. Acquisition of data: Farahmand, Sæhle, Hellström, Wikkelsö. Analysis and interpretation of data: Farahmand, Sæhle, Hellström, Wikkelsö. Drafting the article: Farahmand, Sæhle, Tisell, Hellström, Wikkelsö. Critically revising the article: all authors. Reviewed submitted version of manuscript: all authors. Approved the final version of the manuscript on behalf of all authors: Farahmand. Statistical analysis: Farahmand, Wikkelsö. Study supervision: Eide, Tisell, Wikkelsö.

\section{Correspondence}

Dan Farahmand, Department of Neurosurgery, Sahlgrenska University Hospital, Bla straket 5, van 3, Gothenburg 413 45, Sweden.email: dan.farahmand@vgregion.se. 